\title{
Individuals' adoption of smart technologies for preventive health care: a structural equation modeling approach
}

\author{
${ }^{12}$ Debora Bettiga, ${ }^{1}$ Lucio Lamberti \& ${ }^{1}$ Emanuele Lettieri \\ ${ }^{1}$ Department of Management, Economics and Industrial Engineering - Politecnico di Milano, Via \\ Lambruschini 4B - 20156 Milan (Italy)
}

Corresponding author: ${ }^{2}$ debora.bettiga @ polimi.it; +39 022399 2816;

\begin{abstract}
Healthcare is moving towards new patterns and models, with an increasing attention paid to prevention. Smart technologies for mobile health care are emerging as new instruments to monitor the state of essential parameters in citizens. A very debated subject in literature is the critical role played by citizens' acceptance and willingness to pay for mobile health technologies, especially whereas the services provided are preventive rather than curative. The adoption of such technologies is, indeed, a necessary condition for the success of mobile personalized health care. In this view, a conceptual framework, grounded on Technology Acceptance Model, is developed to explore the determinants of users' willingness to adopt and pay for a mobile health care application for cardiovascular prevention. Empirical data are collected from a sample of 212 non-hypertensive Italian individuals and analyzed through Structural Equation Modeling. Results confirm that usefulness and ease of use determine both intention to accept and willingness to pay for mobile health smart technologies. Results show also the significant role played by social influence as well the role as antecedents played by technology promptness, innovativeness and prevention awareness. This study offers novel insights to design and promote smart application to improve mobile health care, with implications for researchers and practitioners in health care, research \& development, and marketing.
\end{abstract}


Keywords: preventive health; mobile health care; smart technologies; technology acceptance model; structural equation modelling;

\section{Introduction}

The need to face aging population and chronic diseases with, on the one hand, innovative but more expensive health technologies and, on the other hand, with specialized but with higher salaries health professionals is mining the sustainability over time of the national healthcare systems as we know them nowadays $[1,2]$. Health professionals and scholars of different disciplnes such as health care management science, health policy and innovation management are dealing with a variety of strategies and initiatives for modernizing care delivery. In this regard, among the others, the dehospitalization of care delivery [3] and the promotion of disease prevention are emerging as promising strategies to switch the focus of health care from being supplier-centric to be patientcentric [4]. Preventive health care is a powerful instrument to create awareness and contain diseases within the population [5]. This comes either in the form of guidelines and screenings for healthy individuals or in the form of early detection of diseases in risk groups [6].

Smart technologies for mobile health (mHealth) - i.e., intelligent interactive systems usually connected to the Internet and accessible through smartphones - can be effectively used by individuals to directly access new forms of care and prevention [7-11]. These technologies, by enabling new models of delivery and care, have been envisioned as one of the most promising solutions for guaranteeing high-quality, safe and low-cost care delivery in the most developed countries [12]. Against this picture, past research showed that mHealth technologies are hardly accepted by individuals for a variety of reasons, such as lack of system usability, poor training on how to use the system, lack of ICT skills, low perceived self-efficacy, privacy and security concerns, etc. $[13,14]$. Despite the value of past studies, our current understanding of which aspects of mHealth technologies are valued by different types of patients/citizens is still far from being solid $[15,16]$. Past studies focused mainly on the functional drivers of mHealth acceptance, such as 
perceived usefulness, ease of use, level of usage, access, and support provided $[8,17,18]$ with the drawback of overlooking "affective" drivers. Though the success of mobile technologies lays also in the user experience and the new forms of collaboration and social interaction delivered. This spurs the need to consider additional factors above the mere functional ones. Furthermore, despite several models of technology acceptance have been developed to date, they are not appropriate to explain the acceptance of mHealth systems by individuals, because of the peculiarity of the users, of the technologies and of the setting. Health care is, indeed, a professional and knowledge-intensive context that differs greatly from the commercial, product-driven contexts analyzed by mainstream research [19]. Additionally, past contributions set in the health care context focused mainly on chronic patients, whose motivation to accept eHealth and pay for it are 'forced' by the severity of their disease. Vice-versa little has been told so far about individuals who are healthy and are interested to prevent future diseases and maintain their current health status. This area of investigation is relevant for at least three main reasons. First, the use of mobile smart technologies for health prevention may represent a paramount lever for early diagnosis/detection. From an individual perspective, it may lead to higher life expectancy, wellbeing, and less invasive therapies. Second, from a health care system perspective, such technologies may represent a lever through which 'nudging' virtuous conducts by citizens, decreasing the insurgence of diseases that commit relevant resources. Third, healthy people - expecially those who are ageing - represent an emerging and relevant market worldwide. Enlarging the set of users from patients only to healthy people can expand the market size for the technologies and their accessibility in term of price for both individuals and the health care systems.

As the widespread adoption of mHealth systems by the population is desirable, providing the possibility to improve the quality of clinical research and health care on a global scale $[16,20]$, the in-depth understanding of the needs and expectations that drive individuals' adoption of these services is essential [12]. Coherently to this background, this study aims at defining and empirically testing a model for mHealth technology acceptance. To this aim, we extend the well-established 
Technology Acceptance Model (TAM) [21] in the peculiar case of mobile applications for preventive health care. A structural equation modeling approach will be used to test our hyphoteses, as it enables the estimation of the multiple and interrelated factors affecting individuals' adoption in a single analysis [22].

This article proceeds as follows. Section 2 discusses the relevant literature on the subject and develops the main hypotheses. Section 3 describes the methods adopted. Section 4 shows the main findings. Section 5 offers a discussion of the results. Section 6 crystallizes the academic and managerial implications, limitations and suggests avenues for future research.

\section{Literature review and hypotheses}

Technology Acceptance Model (TAM) represents a valuable theoretical ground for explaining the acceptance of mHealth smart systems because of the nature of the technology-enabled services. TAM essentially posits that individual acceptance follows a three-stage process: (i) external factors that refer to individuals' beliefs influence their perceived usefulness (PU), and perceived ease of use (PEOU) toward using the IT system; (ii) PU and PEOU influence the behavioural intention to accept such IT system; finally (iii) behavioural intention influences the actual use of the IT system. PU and PEOU represent the cornerstones of our theoretical framework. Moving from them, we identified from past research three antecedents of them: prevention awareness, technology promptness, and innovativeness. Prevention awareness represents the extent to which the individual perceives prevention as a relevant, effective conduct for his/her health. This is an antecedent of perceived usefulness in our framework. Technology promptness denotes the availability of a technology when and where is needed. It is assumed as an antecedent of perceived ease of use. Innovativeness represents the individual openness to new technologies. It is anticipated as an antecedent of perceived ease of use. Identifying the drivers of usefulness and ease of use is key. The accessibility of mobile health care, indeed, is increasing, thanks to the diffusion of smartphones, tablets and wearable devices. However, even if barriers to health care access are reducing, it must 
be noted that mobile health care systems are targeting more and more elderly people, potentially less prone to adopt them because they are less 'IT literated'. For this reason, exploring the drivers of perceived usefulness and ease of use may provide interesting insight into strategies, at a company and at a policy-making level alike, to boost the diffusion of smart systems for mobile health care. Finally, we extended TAM by considering subjective norm as a main determinant of acceptance. Subjective norm reflects the social pressure generated by a sense of compliance with others' expectations. This assumption has a twofold rationale. First, individuals, as embedded in a social context, may exchange information and receive pressures from relatives, friends, health professionals, colleagues and peers about their health and lifestyle conduct. Understanding the impact of these external forces in promoting/inhibiting the adoption of mobile health technologies represents a valuable insight. Second, TAM, yet considered a reference theory to analyze technology acceptance in the health care industry [17, 19], has been often criticized for considering the functional side of acceptance only [23]. However, technology adoption is not just about functional, task-related evaluations, such as perceived usefulness, ease of use or network externalities [24-26]. It depends on a more complex set of variables that touch the personal and the social-self of the adopter and the external pressure he receives from peers, family and communities $[27,28]$. Hence, including social factors in TAM should provide a richer understanding of the phenomenon investigated.

Intention to accept (ITA) and willingness to pay (WTP) represent the two decision-making constructs of our model. The former (ITA) represents the conscious propensity to adopt smart technologies for health care. It is the outcome variable of TAM-based models and has shown to be strongly related to actual adoption $[21,29,30]$. In our model, yet, we went beyond mere intention to accept, investigating whether the intention to accept may lead also to the willingness-to-pay for the service. While therapies are either provided for free or covered by personal health insurances in most industrialized countries, preventive medicine typically entails a voluntary out-of-pocket 
payment to access the service. Such payment may inhibit the actual transformation of the intention in the adoption. In this view, understanding the determinants of the WTP may favour the uptake of how smart systems for mHealth may diffuse in practice. Our argument is that WTP depends on ITA. This is supported by past studies $[31,32]$ that showed that WTP is a consequence of a positive attitude towards technology adoption. This imply that acceptance is not influenced by price-related issues, allowing us to separate the technology evaluation from the economic evaluation. The conceptual framework explaining healthy individuals' intention to accept and pay for mHealth smart technologies is presented below (Fig. 1). Its main constructs and relationships are detailed briefly in the followings.

\section{Fig. 1 Conceptual Framework}

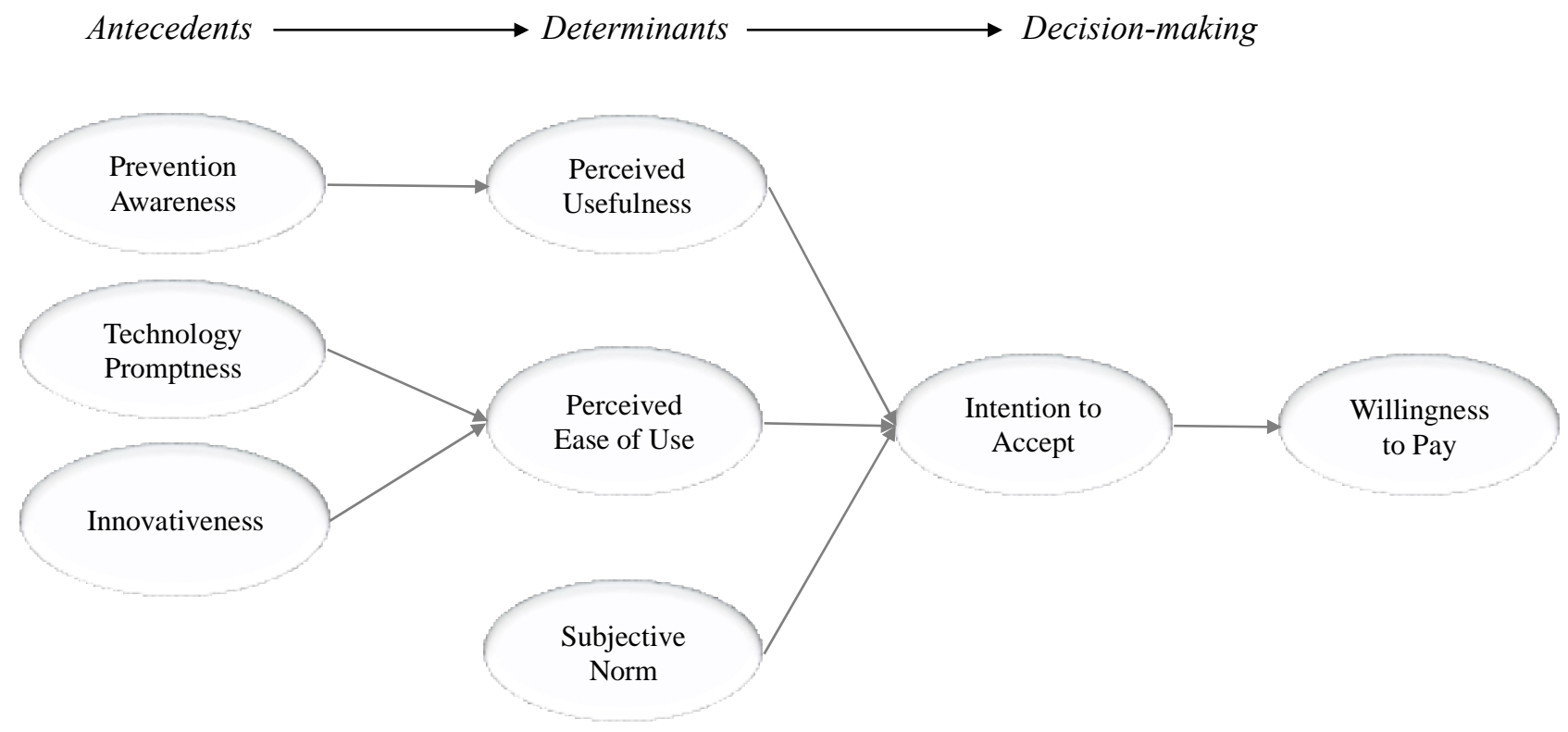

\subsection{Perceived Usefulness}

Perceived usefulness plays a central role in explaining user behaviors toward technologies [21]. It is defined as the degree to which a person believes that using a particular system will enhance his/her performance [21]. It represents the value derived from an effective task fulfillment and is connected with superiority compared with the alternatives [33]. The usefulness of a system is strictly related to its effective and efficient usage [34] and is connected to the convenience, availability or ease of use. In theories about consumption values [35], the functional value is considered as the primary driver 
of consumers' choice. When evaluating a new system, indeed, users are likely to give a great importance to the compatibility of the technology with their personal goals and expectations. The relationship between perceived usefulness and intention to adopt has been widely tested and confirmed by past studies with different contexts, technologies and consumer segments [21, 36] becoming a taken-for-granted relationship in technology acceptance studies. Thus, we formulated the following hypothesis:

H1: Perceived usefulness has a positive influence on intention to accept.

\subsection{Perceived ease of use}

Perceived ease of use refers to the personal belief that using a particular system will be free of effort [21]. PEOU becomes extremely relevant in determining adoption of innovations [37] as permits to compare different technologies in term of saving of time they provide. It is a driver of personal technology usage [38]. The importance of PEOU in predicting technology acceptance has been widely confirmed $[21,30,36]$ and has been acknowledged as a good measure of functional characteristics of a technology [39]. Thus, we formulated the following hypothesis:

H2: Perceived ease of use has a positive influence on intention to accept.

\subsection{Subjective norm}

Our framework integrates the concept of social influence through subjective norm that we argue has a fundamental role in health-related choices and behaviours, although it has not been addressed in prior research on the field. Subjective norm is defined as "an individual's perception of the degree to which important other people approve or disapprove the target behaviour" [40]. Self-care and prevention behaviours are not only motivated by individual beliefs, but often by a sense of compliance to others' expectations that exert a direct social pressure. This social pressure can derive from family members, from the social group the individual belongs to (e.g., the colleagues or the boss) as well as from doctors. The role played by this social pressure has been clearly pointed out in 
past contributions dealing with individuals' engagement in wellbeing-oriented behaviours, such as quit smoking, doing physical activity, being on diet, etc. Furthermore, this social influence can be exerted by other sources, such as other users of the same service or of similar ones, either directly or indirectly by means of reviews, ratings, successful stories. Indeed, individuals are part of complex social networks and communities that might influence their intentions and behaviours. This line of arguments echoes the applications of the Theory of Reasoned Action (TRA) to behavioural changes in health care [41]. Following this reasoning, we formulated the following hypothesis:

\section{H3: Subjective norm has a positive influence on intention to accept.}

\subsection{Intention to accept and willingness to pay}

Intention represents a person's decision or plan to perform an individual act (or achieve a goal) by himself/herself and it is a predictor of his/her interest in using the system in the future [42]. Behavioral intention is, along with willingness to pay, the focal decision-making variable of our frame, as it showed to be a reliable predictor of technology adoption [43, 44]. Providing preventive services in many European countries faces, indeed, the barrier that individuals' expectations are for services delivered for free as part of the tax-funded national health care service. This is a fundamental endpoint for mHealth preventive services based on fees out-of-pocket for users. In this regard, willingness to pay (WTP) has been included as a salient variable in our model. Health care professionals who are launching mobile health care services leveraging on the opportunities offered by smart technologies, need to know how to promote these services among the population. Device usage patterns of individuals with limited budget, indeed, have shown to be highly influenced by monetary considerations; even desirable products, in some cases, are not adopted because of the price constraint [45]. Thus, we formulated the following hypothesis:

H4: Intention to accept has a positive influence on willingness to pay.

\subsection{Prevention awareness}


Health prevention is difficult to mandate. On the one hand, prevention might be a significant strategy to guarantee the sustainability of the health care systems of the most developed countries in the mid/long-term as result of the decrease of chronic patients and hospitalizations. On the other hand, prevention shows its benefits only in the mid/long-term, meaning that individuals' motivation should last for years, or decades, for experiencing a benefit. Sustaining and reinforcing over time such motivation is salient for any prevention-oriented initiative and technology-enabled service. In this regard, being aware of the role that prevention might play is conducive of desirable behaviours in individuals, with favorably impact on disease treatment [46-48]. This is particularly true for minorities and for groups with less education, in whom awareness is lower and thus the risk of disease increases [46]. Following this line of arguments, we formulated the following hypothesis:

\section{H5: Prevention awareness has a positive influence on perceived usefulness.}

\subsection{Technology promptness}

Perceived technology promptness expresses all the contingent conditions that spur the use of a technology, such as its immediate availability when needed or other contextual drivers of use [33]. Context is a key issue in human-technology interaction, able to affect user attitude and influence acceptance. This is particularly relevant for mobile health, that needs technological solutions enabling to take care of patients anywhere and at anytime. Technology promptness delivers benefits of time and place to users, immediate service access and use [49]. The benefits are not derived from the product or service itself but from its continuous and prompt availability when needed. Technology accessibility is a critical requisite: the more accessible a technology is, the less effort is needed to use it [50]. By facilitating access and use, we assume that technology promptness is a relevant antecedent of perceived ease of use. Following this line of arguments, we formulated the following hypothesis:

H6: Technology promptness has a positive influence on perceived ease of use.

\subsection{Innovativeness}


We modelled personal innovativeness - i.e. the individual's willingness to try out new technologies [51] - as an antecedent of perceived ease of use. Innovativeness can be defined as the individual mental readiness to embrace and use new technologies for achieving personal or work-related goals [52]. It is a state of mind, generated by mental enablers that determine individual inclination toward the acceptance of new technologies [53]. When evaluating the adoption of new products or services, in addition to the assessment of their characteristics, the individual's beliefs about innovative technologies may affect perceptions of ease of use [54]. Further, a causal relation between selfefficacy and ease of use perception has been indicated by previous research $[55,56]$. Hence, we propose that innovators perceive a lower technology complexity. Thus, we formulated the following hypothesis:

H7: Innovativeness has a positive influence on perceived ease of use.

\section{Methodology}

\subsection{Measurements}

Survey method was applied to test the hypotheses. The first step was the survey development. Scales were adapted from prior research to measure intention to accept (ITA) [42], perceived usefulness (PU) and perceived ease of use (PEOU) [30], subjective norm (SN) [57], technology promptness (TECH) [49], innovativeness (INN) [51] and willingness to pay (WTP) [58]. Items were measured using Likert scales, with the anchors being 'strongly disagree' and 'strongly agree'. Prevention awareness (PREV) and state of health $(\mathrm{SH})$ - this latter variable helped us discriminating hypertensive and healthy individuals - were measured through scales used in practitioners' standard questionnaires. Above that, the survey included questions on demographic information of age, gender, income and education level. The questionnaire is reported in Appendix A. After the development of the instrument, the second step was the review of the questionnaire for content validity by scholars of health care management and marketing. The third step consisted in a 
pre-test of the questionnaire on a sample of consumers to fine-tune the wording and avoid potential misunderstanding or ambiguous interpretations.

\subsection{Survey delivery}

The final step consisted in the distribution of the survey to Italian consumers. Italy is a significant location for research on preventive mHealth services for many reasons: (i) ageing and chronic diseases are absorbing more and more public resources, mining the capability to fund prevention initiatives; (ii) prevention has been acknowledged as key for baby boomers who are healthy today but will need care in the next future; (iii) Italian citizens are not used to out-of-pocket payments for prevention; and (iv) the penetration of mobile devices is very high.

For this study, we had the opportunity to leverage on a consumer-oriented mHealth application that was still to enter the market. The application is intended for remote blood pressure monitoring. It enables the user to upload and send his/her daily blood pressure values to a medical center to receive feedbacks and, in case of need, either remote or vis-à-vis assistance. Blood pressure monitoring is widely known by the Italian population for being important not only for hypertension management but also for promoting the awareness of cardiovascular risks and consequently prevent cardiovascular events. By referring to a specific mHealth service, we wanted to eliminate potential confounding factors on intention and/or willingness to pay as respondents might refer to different mHealth services when answering.

\section{Results}

We collected 283 completed, high-quality responses. 71 answers were not further considered because they came from hypertensive people and thus out of scope with respect to our interest for 
prevention and healthy individuals. Thus, the final sample size was of 212 answers, equally distributed between males and females. Demographic statistics are reported in Appendix B.

\subsection{Partial Least Square Structural Equation Modeling analysis (PLS-SEM)}

We used Partial Least Squares Structural Equation Modeling (PLS-SEM), a second-generation multivariate data analysis method that allows testing linear and additive models. PLS-SEM is increasingly used in the health care research, being an appropriate and robust method to analyze composite models in exploratory research [59]. We did not opt for first-generation techniques due to their limited capabilities in terms of causal and complex modeling [60]. Among secondgeneration techniques, we opted for PLS-SEM, instead of covariance-based SEM, due to the explorative type of research and the complexity of the structural model - i.e. many constructs and many indicators- [59, 61], that make the use of PLS-SEM more advisable [62]. We do not exclude that other methods may be similarly applied, however SEM is a broadly adopted and accepted method to study TAM-based models (e.g., [63]) and has been successfully applied to comparable research frameworks in health care research in order to predict health behaviors [64]. The method has been proffered as a valid support in predictive behavioral analysis and its use has been encouraged in health behavioral research [65]. Constructs included in the analysis were: perceived usefulness, perceived ease of use, subjective norm, innovativeness, prevention awareness, technology promptness, intention to accept and willingness to pay. Our sample size $(n=212)$ was more than ten times the largest number of structural paths directed to a particular latent construct in the structural model, thus meeting the rule of thumb suggested by Barclay et al. [66]. Our model was balanced in the weight of endogenous and exogenous constructs, meeting PLS-SEM's prediction goal [67]. All our constructs were reflective.

\subsection{Measurement model}

We examined the reliability and validity of constructs [68] through composite reliability, average variance extracted (AVE) and AVE square root (Table 1). We assessed internal consistency 


\begin{tabular}{|c|c|c|c|c|c|c|c|c|c|c|}
\hline Construct & $\begin{array}{l}\text { Composed } \\
\text { Reliability }\end{array}$ & $\begin{array}{l}\text { Average } \\
\text { Variance } \\
\text { Extracted }\end{array}$ & $I N N$ & ITA & PEOU & PREV & $P U$ & SN & TECH & WTP \\
\hline INN & 0.83 & 0.71 & 0.84 & & & & & & & \\
\hline ITA & 0.99 & 0.96 & 0.24 & 0.98 & & & & & & \\
\hline PEOU & 0.96 & 0.88 & 0.49 & 0.26 & 0.94 & & & & & \\
\hline PREV & 0.88 & 0.71 & 0.09 & 0.14 & -0.02 & 0.85 & & & & \\
\hline PU & 0.94 & 0.85 & 0.20 & 0.37 & 0.29 & 0.32 & 0.92 & & & \\
\hline SN & 0.98 & 0.93 & 0.18 & 0.37 & 0.20 & 0.26 & 0.56 & 0.97 & & \\
\hline TECH & 0.92 & 0.80 & 0.48 & 0.32 & 0.62 & 0.05 & 0.31 & 0.26 & 0.89 & \\
\hline WTP & 0.92 & 0.80 & 0.04 & 0.31 & 0.12 & 0.13 & 0.28 & 0.19 & 0.15 & 0.90 \\
\hline
\end{tabular}

reliability of constructs through composite reliability, a more appropriate indicator than Cronbach's alpha [69]. While Cronbach's alpha assumes that all indicators are equally reliable, PLS prioritizes indicators according to their reliability, resulting in a more reliable composite. Indicator reliability was assured through the mean of the squared outer loadings. All indicators were above the minimum threshold recommended of 0.4 and close or above the suggested level of 0.7 [70]. Convergent validity, measuring the latent construct ability to explain a great share of the variance of its indicators, was measured through AVE numbers. The lowest value is 0.71 , higher than the suggested threshold of 0.5 [71]. We assessed discriminant validity with two criteria. First, we used Fornell and Larcker's criterion [72], which assesses discriminant validity on the construct level and imposes the square root of AVE to be greater than the correlations among the latent variables. All our AVE square roots were highly satisfying this condition. Second, we assessed the loading of each indicator that is expected to be greater than all of its cross-loadings [73], evaluating discriminant validity on the indicator level. We satisfied this criterion as well.

\subsection{Common method variance}

Common method variance can be an issue when self-reported questionnaires are used to collect answers from the same key informant at the same time. It represents the variance that may be attributed to the measurement method rather than the constructs the measures represent. To assure 
that common method variance will not affect our results, we developed the survey using different scales types (Likert-scale; multiple choices) and we randomized the order of the items. Further, the complicated specifications in the regression model make it difficult for respondents to anticipate relationships in the framework or use a cognitive map in answering. We examined the robustness of results through Harman's one-factor test [74]. This test assesses the presence of common method variance by indicating whether a single latent factor offers an acceptable alternative explanation of the analysis. We conducted an exploratory factor analysis where all variables were loaded onto a single latent factor and constrained so that there is no rotation [74]. Results show that the single factor was explaining less than $50 \%$ of the variance, thus we concluded that common method variance does not present a significant threat to this study.

\subsection{Structural model}

We run 5,000 bootstrap samples as suggested by Hair et al. [62] and we used the 'no sign changes' criteria, as the most conservative one. The number of iterations to find convergence was 4 , suggesting the goodness of the model. The predictive relevance of our model has been assessed through Stone-Geisser's [75, 76] using blindfolding procedures [77]. Results are shown in Table 2. PEOU, PU, ITA, and WTP showed values above zero, thus confirming the predictive relevance of the constructs in the model. PU, PEOU, and SN are confirmed as predictors of intention to accept, thus confirming HP1, HP2, and HP3. $R^{2}$ of intention is 0.2 . Intention, in its turn, is a predictor of the willingness to pay with an $R^{2}$ of 0.13 , confirming HP4. Effect sizes were satisfactory, according to Cohen $(1988)^{1}$. The inner model results suggest a great influence of innovativeness and technology promptness on PEOU. Further, they show a significant impact of prevention awareness on PU. These results confirm HP5, HP6, and HP7. $R^{2}$ of PEOU is 0.43 and of PU is 0.11 , showing

\footnotetext{
${ }^{1}$ Cohen [78] describes $f^{2}$ values of $0.02,0.15$, and 0.35 as small, medium and large effects, respectively.
} 
moderate and small values respectively that according to Chin (1998) are appropriate for our typology of research ${ }^{2}$.

\begin{tabular}{|c|c|c|c|c|}
\hline \multicolumn{5}{|c|}{ Table 2 Results summary for structural model ${ }^{a}$} \\
\hline & Path Coefficient & $S E$ & $f^{2}$ & $q^{2}$ \\
\hline INN $\rightarrow$ PEOU & $0.26 * * *$ & 0.07 & 0.09 & 0.07 \\
\hline ITA $\rightarrow$ WTP & $0.31 * * *$ & 0.06 & & \\
\hline PEOU $\rightarrow$ ITA & $0.15^{* *}$ & 0.08 & 0.03 & 0.02 \\
\hline PREV $\rightarrow$ PU & $0.32 * * *$ & 0.06 & & \\
\hline PU $\rightarrow$ ITA & $0.19 * *$ & 0.08 & 0.03 & 0.03 \\
\hline SN $\rightarrow$ ITA & $0.23 * * *$ & 0.09 & 0.05 & 0.04 \\
\hline \multirow[t]{2}{*}{ TECH $\rightarrow$ PEOU } & $0.49 * * *$ & 0.06 & 0.33 & 0.26 \\
\hline & $R^{\wedge} \mathbf{2}$ & $Q^{\wedge} 2$ & & \\
\hline PEOU & 0.43 & 0.38 & & \\
\hline PU & 0.11 & 0.08 & & \\
\hline ITA & 0.2 & 0.19 & & \\
\hline WTP & 0.09 & 0.07 & & \\
\hline$N=212^{a}$ & & & & \\
\hline
\end{tabular}

\subsection{Total effects}

We evaluated the total effects in our model, considering both constructs' direct effects and indirect effects via one or more mediating constructs. This is to verify whether additional paths, not specified in the hypothesized model, are significant. Table 3 shows the results for the total effects (direct plus indirect effects).

\begin{tabular}{lll}
\multicolumn{3}{l}{ Table 3 Results summary for structural model - Total effect } \\
\hline Relationships & Path Coeff & SE \\
\hline INNO $\rightarrow$ ITA & 0.04 & 0.02 \\
\hline INNO $\rightarrow$ WTP & 0.01 & 0.01 \\
\hline PEOU $\rightarrow$ WTP & 0.05 & 0.03 \\
\hline PREV $\rightarrow$ ITA & 0.07 & 0.03 \\
\hline PREV $\rightarrow$ WTP & 0.02 & 0.01 \\
\hline PU $\rightarrow$ WTP & $\mathbf{0 . 0 6 * *}$ & $\mathbf{0 . 0 3}$ \\
\hline SN $\rightarrow$ WTP & $\mathbf{0 . 0 7 * * *}$ & $\mathbf{0 . 0 3}$ \\
\hline
\end{tabular}

${ }^{2}$ Chin [73] describes $R^{2}$ values of $0.67,0.33$ and 0.19 in PLS path models as substantial, moderate, and small, respectively, with a moderate value that is acceptable for explorative models or if the endogenous construct has only a few predictors. 


\begin{tabular}{lll}
\hline TECH $\rightarrow$ ITA & 0.08 & 0.04 \\
\hline TECH $\rightarrow$ WTP & 0.02 & 0.01 \\
\hline
\end{tabular}

We found a direct effect of PU on WTP and of SN on WTP. Although these effects are not very strong, they are significant in explaining WTP. These results suggest that PU and SN influence WTP through both direct and indirect effect (mediated by ITA).

The model below (Fig. 2) summarizes results including both direct and indirect effects.

Fig. 2 Relationships among constructs

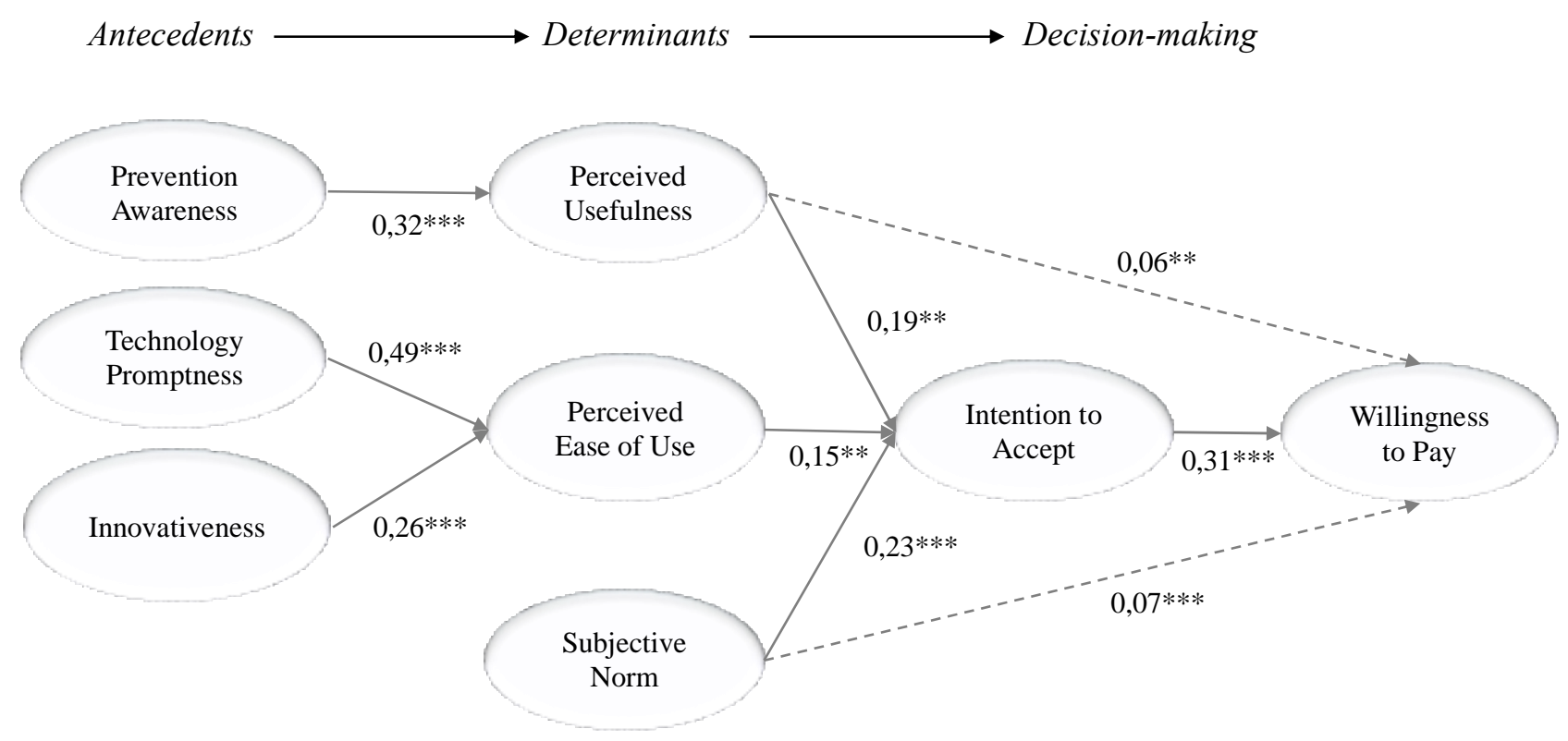

\section{Discussion and implications}

Our results support all the hypotheses developed for this study. In particular, it is possible to outline four main contribution areas, examined in the following: (i) the antecedents of technology perceived usefulness; (ii) the antecedents of technology perceived ease of use; (iii) the impact of subjective norm on intention to accept mHealth technology, and (iv) the antecedents of individuals' willingness to pay. They suggest immediate implications for scholars in health care management, health policy, technology and innovation, marketing, etc.; for policy-makers willing to diffuse preventive services for health care as a mean to decrease the incidence and costs of chronic diseases and hospitalization; and for entrepreneurs or companies that are developing and launching mHealth 
solutions.

\subsection{Antecedents of technologies' perceived usefulness: prevention awareness}

In our study, perceived usefulness is positively affected by prevention awareness. Thus, individuals who are aware of the importance of prevention evaluate the technology-enabled service as more useful. This result is not surprising in itself, but it shows how the diffusion of mobile technologies for health care prevention may be fostered by a proper communication about the relevance and the effectiveness of prevention. Appropriate communication initiatives may dramatically encourage the adoption of these technologies even among healthy individuals.

\subsection{Antecedents of technologies' perceived ease of use: technology promptness and innovativeness}

Our results confirm innovativeness and technology promptness as significant drivers of perceived ease of use. In particular, the relevance of innovativeness demonstrates that personal characteristics matter when evaluating mHealth systems. Individuals with a greater inclination toward new technologies and innovations, regardless the specific category, perceive less complexity in the use of smart technologies, perhaps due to the level of expertise they gained. Thus, providers should offer enough support when targeting consumer segments with a lower inclination toward new technologies (such as elderly) as they may experience greater barriers in the use of the system. Findings for technology promptness confirm that the more accessible a mHealth system is the fewer effort individuals perceive in using it. Providing ubiquitous and immediate access to preventive health care systems will consistently reduce the usage complexity in the eyes of the user.

\subsection{Subjective norm on intention to accept smart technologies for mHealth}

Our results crystallize how the inclusion of subjective norm actually enriches the understanding offered by the traditional TAM with respect to the intention to accept preventive mHealth smart applications. Indeed, we demonstrate that, in healthy individuals, subjective norms impact on the overall intention to accept preventive mHealth technologies. Such an outcome is a relevant 
theoretical contribution, extending TAM and paving the way for future research about the role that social factors play on acceptance of health technologies aimed at prevention. The lack of compulsory behaviours as a response to specific diseases clarifies that preventive behaviours emerge and are shaped in socially-embedded environments. Here individuals' willingness is reinforced by relevant and trusted others. This result testifies that 'proper' external pressures, even in healthy individuals, may lead to the adoption of preventive lifestyles, independently from the perceived usefulness and ease of use of the system. For this reason, future research on the adoption of preventive conducts cannot neglect the role played by subjective norm. Both practitioners and researchers should take this result into account, and design proper initiatives to generate consensus in the community surrounding the targeted users. It is interesting to match this result with the conspicuous literature positing the relevance of network-related externalities in technology adoption $[54,79]$. This raises a hypothesis, which we recommend for future studies, that the adoption of a preventive lifestyle may be encouraged by the concurrent presence of social pressure and the availability of dedicated health technologies.

\subsection{Antecedents of willingness to pay: intention to accept, perceived usefulness and subjective} norm

Empirical evidence supports the claim that willingness to pay increases as the overall intention to accept increases. It also shows a direct effect of perceived usefulness and subjective norm on willingness to pay. This result raises a series of intriguing implications. First and foremost, the direct, unexpected impact of subjective norm on willingness to pay suggests that third parties may lead individuals to commit money in preventive technologies. This does not only reinforce the salience of subjective norm in acceptance of preventive mHealth technologies but depicts the strong relevance of these norms in 'motivating' individuals to pay for these services. This suggests that individuals rely heavily on referents when they make purchases that affect their health. Thus, providers of such services should turn their attention to referents, communicating directly to 
physicians and pharmacists the benefits achievable by the use of mHealth technologies. Further, communication should tap the whole family and individual's social group, eventually able to influence individuals' willingness to pay for these services. Second, results highlight that perceived ease of use is not able by itself to increase willingness to pay, whilst perceived usefulness and subjective norm are. This outcome has important implications for practitioners and policy-makers, as it suggests that usability and ease of use are surely relevant to make individuals prone to use the technology but are not enough. A boost is needed in the perceived usefulness and/or in the social desirability, to increase the individuals' willingness to pay for it. Providing a user-friendly technology and interface together with an easily understandable system, even if they are important determinants of the intention to accept, is not enough to spur the purchase. Thus, providers of mHealth smart technologies should not limit their efforts solely to lower the complexity of the systems, but they should communicate and promote the utility of preventive health care systems both to the target individuals and to people pertaining to their social environment.

\section{Conclusions, limitations and future developments}

This study offers original insights on the factors driving acceptance of smart technologies for preventive mHealth, a new and growing research field that is going to be in the agenda of both technology developers and health care managers in the years to come. As value shifts to consumers, indeed, the success of health care providers' strategies are embedded in their capability to provide individual-centered and personalized value. Through an empirical study on cardiovascular prevention, we investigated, among other variables, the social influence and the drivers of individuals' willingness to pay. We analyzed data through structural equation modeling, a method able to estimate the constructs interrelated dependences in a single analysis. We showed that social influence and perceived usefulness have a direct impact on willingness to pay for smart technology for preventive health care. On the contrary, perceived ease of use encourages adoption but does not seem able to boost willingness to pay by itself. 
The study has a number of limitations, that suggest immediate future research. First, we based our results on an empirical research on cardiovascular prevention. We encourage other studies exploring different technologies and different diseases to test the generalizability of our results to other contexts. Second, the study deals with Italian citizens. Accounting for cultural factors may generalize the outcomes at an international level. Third, we focused our study on specific sets of individual determinants in order to better shape the antecedents of intention and willingness to pay. Hence, we encourage future studies to encompass such analysis in a broader perspective, including also the effect of network externalities (e.g., the perceived availability of smart mobile technologies) and, foremost, an analysis of the actual adoption by individuals. Finally, it must be reminded that our study has focused on technology acceptance, which is the first necessary condition for the improvement of mHealth care through the application of smart technologies. This is the final goal of this stream of research, and this study represents a first, fundamental cornerstone to understand how smart technologies might really lead to an improvement of social health, individual health, and healthcare system efficiency.

\section{References}

1. Worrall P, Chaussalet TJ (2015) A structured review of long-term care demand modelling. Health Care Manag Sci 18:173-194 . doi: 10.1007/s10729-014-9299-6 [doi]

2. Mallor F, Azcárate C, Barado J (2015) Optimal control of ICU patient discharge: from theory to implementation. Health Care Manag Sci 18:234-250 . doi: 10.1007/s10729-015-9320-8

3. Demirbilek M, Branke J, Strauss A (2018) Dynamically accepting and scheduling patients for home healthcare. Health Care Manag. Sci. 1-16

4. Osei-Frimpong K, Wilson A, Lemke F (2016) Patient co-creation activities in healthcare service delivery at the micro level: The influence of online access to healthcare information. 
Technol Forecast Soc Change 126:14-27 . doi:

http://dx.doi.org/10.1016/j.techfore.2016.04.009

5. Davari S, Kilic K, Ertek G (2015) Fuzzy bi-objective preventive health care network design. Health Care Manag Sci 18:303-317 . doi: 10.1007/s10729-014-9293-z

6. Cohen JT, Neumann PJ, Weinstein MC (2008) Does Preventive Care Save Money? Health Economics and the Presidential Candidates. N Engl J Med 358:661-663 . doi: 10.1056/NEJMp0708558

7. Or C, Karsh B (2009) A systematic review of patient acceptance of consumer health information technology. J Am Med Informatics Assoc 16:550-560

8. Kim D, Chang H (2007) Key functional characteristics in designing and operating health information websites for user satisfaction: An application of the extended technology acceptance. Int J Med Inform 76:790-800

9. Muessig K, Pike E, LeGrand S, Hightow-Weidman LB (2013) Mobile phone applications for the care and prevention of HIV and other sexually transmitted diseases: a review. J Med Internet Res 15:

10. Burke LE, Ma J, Azar KM, et al (2015) Current Science on Consumer Use of Mobile Health for Cardiovascular Disease Prevention: A Scientific Statement From the American Heart Association. Circulation 132:1157-1213 . doi: 10.1161/CIR.0000000000000232

11. Lobelo F, Kelli HM, Tejedor SC, et al (2017) The wild wild west: A framework to integrate mHealth software applications and wearables to support physical activity assessment, counseling and interventions for cardiovascular disease risk reduction. Prog Cardiovasc Dis 58:584-594 . doi: 10.1016/j.pcad.2016.02.007.The

12. Yu P, Wu MX, Yu H, Xiao GQ (2006) The challenges for the adoption of m-health. In: 2006 IEEE International Conference on Service Operations and Logistics, and Informatics, SOLI 
2006. pp 181-186

13. Gustafson DH, Hawkins RP, Boberg EW, et al (2002) CHESS: 10 years of research and development in consumer health informatics for broad populations, including the underserved. Int J Med Inform 65:169-77

14. Slack W V. (1997) Cybermedicine: how computing empowers doctors and patients for better health care. Jossey-Bass Inc., Publishers, San Francisco, CA, USA

15. Wilson E, Lankton N (2004) Modeling patients' acceptance of provider-delivered e-health. J Am Med Informatics Assoc 11:241-248

16. Steinhubl SR, Muse ED, Topol EJ (2015) The Emerging Field of Mobile health. Sci Transl Med 7:1-6 . doi: 10.1126/scitranslmed.aaa3487

17. Pai F, Huang K (2011) Applying the Technology Acceptance Model to the introduction of healthcare information systems. Technol Forecast Soc Change 78:650-660 . doi: 10.1016/j.techfore.2010.11.007

18. Lee E, Han S (2015) Determinants of adoption of mobile health services. Online Inf Rev 39:556-573 . doi: 10.1108/OIR-01-2015-0007

19. Holden R, Karsh B (2010) The technology acceptance model: its past and its future in health care. J Biomed Inform 43:159-172

20. Behkami NA, Daim TU (2012) Forecasting for Health Information Technology ( HIT ), using technology intelligence. Technol Forecast Soc Chang 79:498-508 . doi: 10.1016/j.techfore.2011.08.015

21. Davis F (1989) Perceived usefulness, perceived ease of use, and user acceptance of information technology. MIS Q 13:319-340

22. Ullman JB, Bentler PM (2012) Structural Equation Modeling. In: Handbook of Psychology, 
Second Edition. John Wiley \& Sons, Inc., Hoboken, NJ, USA

23. Bagozzi RP (2007) The Legacy of the Technology Acceptance Model and a Proposal for a Paradigm Shift . J Assoc Inf Syst 8:244-254

24. Gefen D, Straub D (1997) Gender differences in the perception and use of e-mail: An extension to the technology acceptance model. MIS Q 21:389-400

25. Wang C, Lo S, Fang W (2008) Extending the technology acceptance model to mobile telecommunication innovation: The existence of network externalities. J Consum Behav 7:101-110 . doi: 10.1002/cb

26. Edmunds R, Thorpe M, Conole G (2012) Student attitudes towards and use of ICT in course study, work and social activity: A technology acceptance model approach. Br J Educ Technol 43:71-84 . doi: 10.1111/j.1467-8535.2010.01142.x

27. Schepers J, Wetzels M (2007) A meta-analysis of the technology acceptance model: Investigating subjective norm and moderation effects. Inf Manag 44:90-103 . doi: 10.1016/j.im.2006.10.007

28. Svendsen GB, Johnsen J-AK, Almås-Sørensen L, Vitters $\emptyset$ J (2013) Personality and technology acceptance: the influence of personality factors on the core constructs of the Technology Acceptance Model. Behav Inf Technol 32:323-334 . doi:

$10.1080 / 0144929 X .2011 .553740$

29. Davis FD (1993) User acceptance of information technology: system characteristics, user perceptions and behavioral impacts. Int J Man Mach Stud 38:475-487 . doi:

10.1006/imms.1993.1022

30. Venkatesh V, Davis FD (2000) A Theoretical Extension of the Technology Acceptance Model: Four Longitudinal Field Studies. Manage Sci 46:186-204 . doi:

10.1287/mnsc.46.2.186.11926 
31. Schwarz N, Ernst A (2009) Agent-based modeling of the diffusion of environmental innovations — an empirical approach. Technol Forecast Soc Change 76:497-511 . doi: doi:10.1016/j.techfore.2008.03.024

32. Claudy MC, Michelsen C, O’Driscoll A (2011) The diffusion of micro generation technologies - assessing the influence of perceived product characteristics on home owners' willingness to pay. Energy Policy 39:1459-1469

33. Sheth JN, Newman BI, Gross BL (1991) Why we buy what we buy: A theory of consumption values. J Bus Res 22:159-170 . doi: 10.1016/0148-2963(91)90050-8

34. Venkatesh V, Brown S (2001) A longitudinal investigation of personal computers in homes: adoption determinants and emerging challenges. MIS Q 25:71-102

35. Sheth JN, Newman BI, Gross BL (1991) Why We Buy What We Buy. J Bus Res 22:159-171

36. Davis FD, Venkatesh V (2004) Toward Preprototype User Acceptance Testing of New Information Systems: Implications for Software Project Management. IEEE Trans Eng Manag 51:31-46 . doi: 10.1109/TEM.2003.822468

37. Tornatzky L, Klein K (1982) Innovation characteristics and innovation adoptionimplementation: A meta-analysis of findings. Eng Manag IEEE Trans 0n 29:28-45

38. Collier J, Kimes S (2013) Only if it is convenient understanding how convenience influences self-service technology evaluation. J Serv Res 16:39-51

39. Venkatesh V, Davis FD (1996) A Model of the Antecedents of Perceived Ease of Use: Development and Test. Decis Sci 27:451-481 . doi: 10.1111/j.1540-5915.1996.tb01822.x

40. Ajzen I (1991) The theory of planned behavior. Organ Behav Hum Decis Process 50:179211 . doi: 10.1016/0749-5978(91)90020-T

41. Ajzen I, Albarracín D, Hornik R (2007) Prediction and change of health behavior: Applying 
the reasoned action approach. Psychology press. Lawrence Erlbaum Associates, Inc, Mahwah, New Yersey

42. Venkatesh V, Morris M, Davis G, Davis F (2003) User acceptance of information technology: Toward a unified view. MIS Q 27:425-478

43. Davis F, Bagozzi R, Warshaw P (1989) User acceptance of computer technology: a comparison of two theoretical models. Manage Sci 46:186-204

44. Agarwal R, Prasad J (1999) Are individual differences germane to the acceptance of new information technologies? Decis Sci 3:361-391

45. Sarker S, Wells J (2003) Understanding mobile handheld device use and adoption. Commun ACM 46:35-40

46. Folsom AR, Sprafka JM, Luepker R V, Jacobs DRJ (1988) Beliefs among black and white adults about causes and prevention of cardiovascular disease: the Minnesota Heart Survey. Am J Prev Med 4:121-127

47. Folsom AR, Iso H, Sprafka JM, et al (1988) Use of aspirin for prevention of cardiovascular disease-1981-1982 to 1985-1986: The Minnesota Heart Survey. Am Heart J 116:827-830 . doi: 10.1016/0002-8703(88)90344-4

48. Mosca L, Mochari-Greenberger H, Dolor RJ, et al (2010) Twelve-year follow-up of American women's awareness of cardiovascular disease risk and barriers to heart health. Circ Cardiovasc Qual Outcomes 3:120-127 . doi: 10.1161/CIRCOUTCOMES.109.915538

49. Mallat N, Rossi M, Tuunainen VK, Öörni A (2009) The impact of use context on mobile services acceptance: The case of mobile ticketing. Inf Manag 46:190-195 . doi: 10.1016/j.im.2008.11.008

50. Karahanna E, Straub DW (1999) The psychological origins of perceived usefulness and ease- 
of-use. Inf Manag 35:237-250

51. Tsikriktsis N (2004) A Technology Readiness-Based Taxonomy of Customers A Replication and Extension. J Serv Res 7:42-52

52. Parasuraman A (2000) Technology Readiness Index (Tri): A Multiple-Item Scale to Measure Readiness to Embrace New Technologies. J Serv Res 2:307-320 . doi:

$10.1177 / 109467050024001$

53. Liljander V, Gillberg F, Gummerus J, van Riel A (2006) Technology readiness and the evaluation and adoption of self-service technologies. J Retail Consum Serv 13:177-191 . doi: 10.1016/j.jretconser.2005.08.004

54. Lin CH, Shih HY, Sher PJ (2007) Integrating technology readiness into technology acceptance: The TRAM model. Psychol Mark 24:641-657 . doi: 10.1002/mar.20177

55. Wang Y-S, Wang Y-M, Lin H-H, Tang T-I (2003) Determinants of user acceptance of Internet banking: an empirical study. Int J Serv Ind Manag 14:501-519 . doi: $10.1108 / 09564230310500192$

56. Davis FD, Venkatesh V (1996) A critical assessment of potential measurement biases in the technology acceptance model: three experiments. Int J Hum Comput Stud 45:19-45 . doi: 10.1006/ijhc. 1996.0040

57. Ajzen I (2002) Constructing a TPB questionnaire: Conceptual and methodological considerations

58. Gall-Ely M Le (2009) Definition, measurement and determinants of the consumer's willingness to pay: a critical synthesis and avenues for further research. Rech Appl en Mark English Ed 24:91-112

59. Avkiran NK (2018) An in-depth discussion and illustration of partial least squares structural 
equation modeling in health care. Health Care Manag Sci 21:401-408 . doi: 10.1007/s10729017-9393-7

60. Lowry, P. B., \& Gaskin J (2014) Partial least squares (PLS) structural equation modeling (SEM) for building and testing behavioral causal theory: When to choose it and how to use it. IEEE Trans Prof Commun 57:123-146

61. Hwang H, Malhotra N, Kim Y, et al (2010) A comparative study on parameter recovery of three approaches to structural equation modeling. J Mark Res 47:699-712

62. Hair J, Ringle C, Sarstedt M (2011) PLS-SEM: Indeed a silver bullet. J Mark Theory Pract 19:139-152

63. Gefen, D., Straub, D., \& Boudreau MC (2000) Structural equation modeling and regression: Guidelines for research practice. Commun Assoc Inf Syst 4:1-77

64. Schwarzer R (2008) Modeling health behavior change: How to predict and modify the adoption and maintenance of health behaviors. Appl Psychol 57:1-29

65. Buhi, E. R., Goodson, P., \& Neilands TB (2007) Structural equation modeling: a primer for health behavior researchers. Am J Health Behav 31:74-85

66. Barclay D, Higgins C, Thompson R (1995) The Partial Least Squares (PLS) Approach to Causal Modelling: Personal Computer Adoption and Use as an Illustration. Technol Stud $2: 285-309$

67. Hair J, Sarstedt M, Ringle C, Mena J (2012) An assessment of the use of partial least squares structural equation modeling in marketing research. J Acad Mark Sci 40:413-433

68. Haenlein M, Kaplan A (2004) A beginner's guide to partial least squares analysis. Underst Stat 3:283-297

69. Werts C, Linn R, Jöreskog K (1974) Intraclass reliability estimates: Testing structural 
assumptions. Educ Psychol Meas 34:25-33

70. Wong K (2013) Partial least squares structural equation modeling (PLS-SEM) techniques using SmartPLS. Mark Bull 24:1-32

71. Bagozzi RP, Yi Y (1988) On the evaluation of structural equation models. J Acad Mark Sci $16: 74-94$

72. Fornell C, Larcker D (1981) Evaluating structural equation models with unobservable variables and measurement error. J Mark Res 18:39-50

73. Chin W (1998) The partial least squares approach to structural equation modeling. Mod methods Bus Res 295:295-336

74. Podsakoff P, MacKenzie S, Lee J, Podsakoff N (2003) Common method biases in behavioral research: a critical review of the literature and recommended remedies. J Appl Psychol 88:879-903

75. Stone M (1974) Cross-validatory choice and assessment of statistical predictions. J R Stat Soc Ser B 36:111-147

76. Geisser S (1974) A predictive approach to the random effect model. Biometrika 61:101-107

77. Tenenhaus M, Vinzi V (2005) PLS path modeling. Comput Stat Anal 48:159-205

78. Cohen J (1988) Statistical power analysis for the behavioral sciences. Lawrence Erlbaum Associates, Hillsdale, New Jersey

79. Song M, Parry ME, Kawakami T (2009) Incorporating Network Externalities into the Technology Acceptance Model. 23:291-307

\section{Appendix A - Questionnarie}




\begin{tabular}{ll}
\hline Construct & Items \\
\hline $\begin{array}{l}\text { Intention To Accept } \\
\text { (ITA) [42] }\end{array}$ & $\begin{array}{l}\text { I intend to use the system in the next month } \\
\text { I predict I would use the system in the next month } \\
\text { I plan to use the system in the next month }\end{array}$ \\
$\begin{array}{l}\text { Perceived } \\
\text { Usefulness (PU) [30] }\end{array}$ & $\begin{array}{l}\text { Using the system improves my performance in managing high blood } \\
\text { pressure } \\
\text { Using the system increases my ability in managing high blood pressure } \\
\text { I find the system to be useful in managing high blood pressure }\end{array}$
\end{tabular}
Perceived Ease Of My interaction with the system is clear and understandable Use (PEOU) [30] Interacting with the system does not require a lot of my mental effort I find the system to be easy to use
Subjective Norm People who influence my behavior think that I should use the system (SN) [57] People who are important to me think that I should use the system People who are important to me expect me to use the system

Technology
Promptness (TECH)
[49]

Innovativeness (INN) [51]

\section{Using the system is independent of time}

Using the system is independent of place

Using the system is convenient because the smartphone is usually with me

I can usually figure out new high-tech products and services without help from others

In general, I am among the first in my circle of friends to acquire new technology when it appears

\section{Willingness To Pay I am willing to pay the price indicated for the service \\ (WTP) [58] I will subscribe the service at the indicated price \\ I am willing to purchase the service at the indicated price}

Prevention How important is for you to engage in preventive health care?

Awareness (PREV) How important is for you to conduct regular health screenings and check-ups not connected with diagnosed diseases?

Do you believe that preventive healthcare services can help you to improve your state of health?

State Of Health (SH) Have you ever experienced issues with high blood pressure?

Have you ever experiences hypertensive episodes?

\begin{tabular}{lc}
\hline \multicolumn{2}{l}{ Appendix B - Demographic Statistics } \\
\hline Gender \\
\hline Male & $53 \%$ \\
\hline Female & $47 \%$ \\
\hline Age & \\
\hline$<45$ & $48 \%$ \\
\hline
\end{tabular}




\begin{tabular}{lc}
\hline $46-60$ & $27 \%$ \\
\hline $61-70$ & $20 \%$ \\
\hline$>71$ & $4 \%$ \\
\hline Education & \\
\hline Elementary school & $1 \%$ \\
\hline Junior high school & $8 \%$ \\
\hline High school & $49 \%$ \\
\hline University & $42 \%$ \\
\hline Annual income & \\
\hline $0-35.000$ & $58 \%$ \\
\hline $35.001-70.000$ & $26 \%$ \\
\hline $70.001-100.000$ & $5 \%$ \\
\hline$>100.000$ & $3 \%$ \\
\hline missing & $8 \%$ \\
\hline${ }^{a} N=212$ & \\
\hline
\end{tabular}

This is a post-peer-review, pre-copyedit version of an article published in Health Care Management Science. The final authenticated version is available online at: https://doi.org/10.1007/s10729-01909468-2 